\title{
In reply: Fluid management issues in Enhanced Recovery After Surgery and Canadian Anesthesiologists' Society standards
}

\author{
Timothy E. Miller, MBChB • Anthony M. Roche, MBChB • \\ Michael Mythen, MD
}

Received: 2 April 2015/Accepted: 9 April 2015/Published online: 18 April 2015

(c) Canadian Anesthesiologists' Society 2015

\section{To the Editor,}

We thank Drs. Merchant and Davies ${ }^{1}$ for clarifying the wording in our recent review regarding fluid management in Enhanced Recovery After Surgery programs. ${ }^{2}$ We agree that the Canadian Anesthesiologists' Society and the American Society of Anesthesiologists should change their practice guidelines for preoperative fasting to encourage consumption of clear fluids up to two hours preoperatively.

Conflict of interest Dr. Timothy E. Miller: Honoraria - Edwards Lifesciences. Dr. Anthony M. Roche: Consultant for Deltex Medical and PATH. Dr. Michael (Monty) Mythen: Consultant for Deltex,
Edwards Lifesciences; Grants - Deltex, Smiths Medical; Honoraria and travel - Baxter, Fresenius-Kabi.

\section{References}

1. Merchant RN, Davies JM. Fluid management issues in Enhanced Recovery After Surgery and Canadian Anesthesiologists' Society standards. Can J Anesth 2015; 62; DOI: 10.1007/s12630-0150388-x.

2. Miller TE, Roche AM, Mythen M. Fluid management and goaldirected therapy as an adjunct to Enhanced Recovery After Surgery (ERAS). Can J Anesth 2015; 62: 158-68.
T. E. Miller, MBChB $(\bowtie)$

Department of Anesthesiology, Duke University Medical Center, Durham, NC, USA

e-mail: timothy.miller2@duke.edu

\section{A. M. Roche, $\mathrm{MBChB}$}

Department of Anesthesiology, University of Washington,

Seattle, WA, USA

M. Mythen, MD

Institute of Sport Exercise and Health, UCLH National Institute of Health Research Biomedical Research Centre, London, USA 